\title{
The metabolic adaptation mechanism of metastatic organotropism
}

\author{
Chao Wang ${ }^{1}$ and Daya Luo ${ }^{2^{*}}$ (D)
}

\begin{abstract}
Metastasis is a complex multistep cascade of cancer cell extravasation and invasion, in which metabolism plays an important role. Recently, a metabolic adaptation mechanism of cancer metastasis has been proposed as an emerging model of the interaction between cancer cells and the host microenvironment, revealing a deep and extensive relationship between cancer metabolism and cancer metastasis. However, research on how the host microenvironment affects cancer metabolism is mostly limited to the impact of the local tumour microenvironment at the primary site. There are few studies on how differences between the primary and secondary microenvironments promote metabolic changes during cancer progression or how secondary microenvironments affect cancer cell metastasis preference. Hence, we discuss how cancer cells adapt to and colonize in the metabolic microenvironments of different metastatic sites to establish a metastatic organotropism phenotype. The mechanism is expected to accelerate the research of cancer metabolism in the secondary microenvironment, and provides theoretical support for the generation of innovative therapeutic targets for clinical metastatic diseases.
\end{abstract}

Keywords: Cancer metastasis, Cancer metabolism, Organotropism, "Seed and soil" hypothesis

\section{Background}

\section{Cancer metastasis}

Metastasis refers to the process by which cancer cells leave the site of cancer occurrence, arrive at distant organs by various ways, and thrive in distant organs, which is one of the hallmarks of cancer cells [1]. Clinically, approximately $90 \%$ of cancer patients die from metastatic disease, yet the molecular mechanisms underlying metastasis are poorly understood [2]. It is currently believed that cancer metastasis is a dynamic and complex multistep process known as the "metastatic cascade". This cascade includes local invasion of surrounding tissues, intravasation to the blood vessel wall, survival in the circulatory system and formation of circulating tumour cells (CTCs), arrest in a distant organ, extravasation as disseminated tumour cells (DTCs), formation

*Correspondence: luodaya@ncu.edu.cn

2 Department of Biochemistry and Molecular Biology, School of Basic Medical Sciences, Nanchang University, Nanchang 330006, China

Full list of author information is available at the end of the article of micrometastatic clones and colonization in distant organs to form clinically detectable macrometastatic clones [2,3].

In 1889, the English surgeon Stephen Paget discovered that the organs of cancer metastasis are not randomly but selectively distributed; therefore, he proposed the "seed and soil" hypothesis in which cancer cells are referred to as seeds and the destination of metastasis as represented by soil. Cancer cells can spread similar to seeds but can thrive only in congenial soil [4]. Now, this phenomenon of non-random metastasis is known as "metastatic organotropism", or "organ-specific metastasis". The common metastatic organs vary by cancer type and subtype. Prostate cancer often metastasizes to bone [5], while pancreatic cancer and uveal melanoma often metastasize to the liver [6,7]. Breast cancer often metastasizes to multiple organs, such as bone, lung, liver, brain, and distant lymph nodes, but different subtypes of breast cancer have different propensities for metastatic sites [810]. In addition, cancer cells can also exhibit an ordered and hierarchical organ-specific metastatic pattern. For

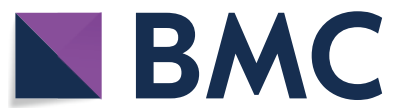

(c) The Author(s) 2021. This article is licensed under a Creative Commons Attribution 4.0 International License, which permits use, sharing, adaptation, distribution and reproduction in any medium or format, as long as you give appropriate credit to the original author(s) and the source, provide a link to the Creative Commons licence, and indicate if changes were made. The images or other third party material in this article are included in the article's Creative Commons licence, unless indicated otherwise in a credit line to the material. If material is not included in the article's Creative Commons licence and your intended use is not permitted by statutory regulation or exceeds the permitted use, you will need to obtain permission directly from the copyright holder. To view a copy of this licence, visit http://creativeco mmons.org/licenses/by/4.0/. The Creative Commons Public Domain Dedication waiver (http://creativecommons.org/publicdomain/ zero/1.0/) applies to the data made available in this article, unless otherwise stated in a credit line to the data. 
example, colorectal cancer usually first metastasizes to the liver and then to the lung [11]. There are many factors that determine metastatic organotropism, including circulatory system patterns, internal characteristics of the cancer, the tissue- or organ-specific microenvironment, and the interaction between cancer cells and the host microenvironment $[3,4,12,13]$. Recently, the metabolic adaptation mechanism of cancer metastasis has been proposed as an emerging model of the interaction between cancer cells and the host microenvironment [14], revealing a deeper internal connection between cancer metabolism and metastasis.

\section{Cancer metabolism}

Metabolic reprogramming is one of the important features in the development and progression of cancer, and it is crucial for the survival and growth of cancer cells [15]. A century ago, German biochemist Otto Warburg first observed that cancer cells undergo metabolic changes. In the case of sufficient oxygen, the anaerobic oxidation of cancer cells is enhanced, oxidative phosphorylation (OXPHOS) is inhibited, and a large amount of glucose produces lactate through glycolysis in a process known as the "Warburg effect" or "aerobic glycolysis" [16]. With the continued in-depth research, more metabolic characteristics of cancer cells have been gradually revealed [17], and cancer metabolism shows incredible flexibility and plasticity. Ketone bodies are mainly produced by the liver but cannot be consumed by normal adult hepatocytes [18]. However, in the absence of nutrients, hepatocellular cancer cells can induce the expression of OXCT1, a key enzyme in ketone catabolism, by activating the mTORC2-Akt-SP1 signalling axis, thereby utilizing ketone bodies to generate energy and support cancer progression [19]. Another study also found there are alternative fatty acid desaturation pathways activated in liver and lung cancer cells [20]. The urea cycle is the main pathway by which ammonia, a metabolic waste, is eliminated from the body. On the one hand, urea cycle initiators and intermediates can be transferred to other metabolic pathways for anabolism [21]; on the other hand, they can also activate metabolism-sensing signalling pathways and exert biological effects distinct from the classical metabolic pathways, demonstrating the strong waste-recycling capacity of cancer cells [22]. In breast cancer, ammonia can be recycled as a nitrogen source by glutamate dehydrogenase and then used in the synthesis of other amino acids, such as proline and aspartate, to support the growing breast cancer biomass [23]. Normally, ammonia-derived CP in mitochondria cannot enter the cytoplasm for pyrimidine synthesis. However, in non-small cell lung cancer (NSCLC) with KRAS mutation and LKB1 deletion, the expression of carbamoyl phosphate synthase (CPS) 1 increases; this change leads to an increase in the $\mathrm{CP}$, which moves from mitochondria to the cytoplasm. Subsequently, the ammonia-derived CP enters the pyrimidine synthesis pathway as a CPS2 substrate to realize waste recycling and support rapid cancer DNA synthesis and fast cell proliferation [24]. One study discovered "urea cycle disorders" in a wide range of cancers. These disorders involve the transfer of nitrogen from the urea cycle; the activation of the multifunctional enzyme CAD protein composed of CPS2, aspartate carbamoyl transferase and dihydroorotase; and the increase in pyrimidine synthesis [25]. In addition, a recent study found that p53 can transcriptionally inhibit the metabolic enzymes CPS1, ornithine transcarbamoylase and arginase 1 in the urea cycle, thereby inhibiting urea synthesis and ammonia clearance. Accumulation of ammonia can significantly downregulate the mRNA translation of the rate-limiting enzyme ornithine decarboxylase in polyamine biosynthesis, thus inhibiting polyamine biosynthesis and cell proliferation [22]. In summary, cancer cells have extremely high metabolic flexibility and can generate energy, support the integrity of the cell membrane structure, synthesize biological macromolecules and regulate gene expression. These biological processes promote the occurrence, survival and development of cancer.

Similar to metastasis, cancer metabolism is not a static and uniform process but a dynamic and heterogeneous process that is mainly determined by the inherent characteristics of cancer cells and the external environment $[15,26,27]$. The inherent characteristics of cancer cells mainly include oncogenic mutations and the tissue of origin. Oncogene and tumour suppressor gene mutations can regulate the metabolic phenotype of cancer through oncogenic signalling pathways. The PI3K-AKT signalling pathway undergoes recurring mutations in a variety of cancers, which enables cells to take up an increased number of nutrients and synthesize biological macromolecules, even in cases of low levels of extracellular growth factor [28]. The inactivating mutations of oncogenes RAS and MYC can also enhance the uptake of glucose and glutamine, increase the biosynthesis of biological macromolecules and maintain energy and redox balance through different mechanisms [29-31]. P53 is a common tumour suppressor gene that is mutated or deleted in approximately $50 \%$ of human cancers. P53 can inhibit glycolysis, enhance OXPHOS and resist oxidative stress [32]. Mutations in metabolic enzymes can also directly regulate metabolic phenotypes. Multiple metabolic enzymes that catalyse the TCA cycle can be mutated; for example, IDH1 and IDH2 mutations can lead to the accumulation of D-2 hydroxyglutarate [33, 34]. SDH and FH mutations lead to the accumulation of succinate and fumarate, respectively [35]. D-2 hydroxyglutarate, succinate and 
fumarate can affect epigenetic modifications and HIF- $1 \alpha$ degradation and participate in the development of cancer [17].

The tissue of origin also affects the metabolic characteristics of the cancer. Through pan-cancer analysis of metabolic gene expression profiles, the metabolic gene expression programme of primary cancer was found to be very similar to that in the normal corresponding source tissues [36, 37]. Moreover, tumours from different tissue origins driven by the same oncogene may have different metabolic patterns. For example, although both are MYC-induced mouse tumours, MYC-induced liver tumours show reduced glutamine anabolism, but MYCinduced lung tumours show increased glutamine anabolism [38]. Kras activation and Trp53 deletion in mouse NSCLC and pancreatic cancer show different types of branched chain amino acid metabolism [39].

In addition to the inherent characteristics of cancer cells, the external environment also has an important impact on metabolism, and cancer metabolism exhibits an environmental dependence (Fig. 1). First, differences between the in vivo and in vitro environments lead to differences in cancer metabolism. Ras-driven NSCLC mainly relies on glucose to supply the TCA cycle in the body and mainly relies on glutamine to supply the TCA cycle in medium [40]. Second, environmental differences between animals and humans also lead to differences in cancer metabolism. Uric acid can directly inhibit uridine monophosphate synthase (UMPS) and reduce the sensitivity of cancer cells to the chemotherapy drug

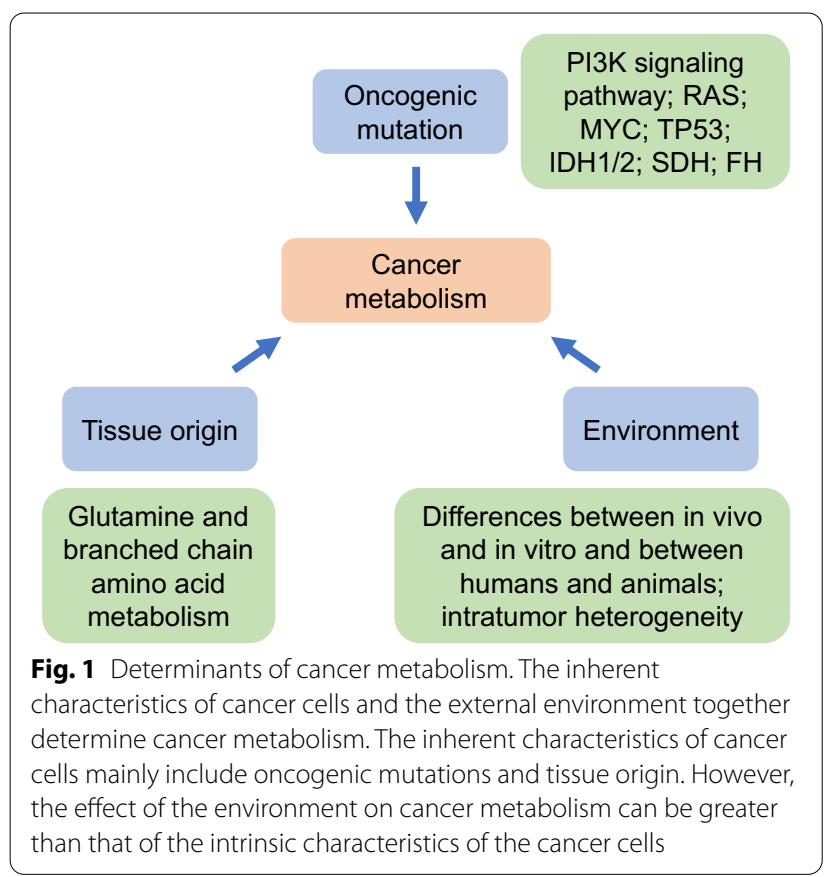

5-fluorouracil [41]; however, the concentration of uric acid in mouse plasma is one-tenth that of human plasma, and therefore the mouse plasma environment shows little effect on UMPS activity or 5-fluorouracil-induced resistance of cancer cells [41]. Subsequently, cells of the same primary cancer located in different environments show metabolic differences. As analysed by preoperative multimodality imaging combined with intraoperative ${ }^{13} \mathrm{C}$-glucose infusions, different areas of NSCLC perfusion showed metabolic heterogeneity [42]. Finally, different cancers in the same environment have similar metabolic patterns. Both gliomas and brain metastases can be fuelled by oxidized glucose and acetate without glutamine oxidation [43]. Therefore, the effect of the environment on cancer metabolism can have an even greater effect than the intrinsic characteristics of the cancer cells.

However, research on how the host microenvironment affects cancer metabolism is mostly limited to the impact of the local tumour microenvironment at the primary site. Few studies have explored how the difference between the primary and secondary microenvironments promotes metabolic changes during cancer progression or how different secondary microenvironments shape different cancer metabolic patterns. Hence, we discuss how cancer cells adapt to and settle in the metabolic microenvironment of different metastatic sites to establish a metastatic organotropism phenotype. The results are expected to accelerate the research of cancer metabolism in the secondary microenvironment and promote the creation of new therapeutic targets for clinical metastatic diseases.

\section{Metabolic adaptation mechanism of metastatic organotropism}

The metabolic adaptation of metastatic organotropism refers to the fact that metabolic pattern of metastatic cancer cells needs to be compatible with the metabolic microenvironment of distant organs to support the survival and growth of metastasizing cancer cells. The metabolic microenvironment that drives cancer metastases to distant organs needs to adapt to acquire sufficient energy, nutrient sources, organ-specific metabolites, and the proper $\mathrm{pH}$, adjust to hypoxic or normoxic conditions, and support metabolic interactions between organ-specific cells and cancer cells. Only a small proportion of DTCs can colonize at a distant site, indicating that the survival and growth of DTCs during colonization requires overcoming significant obstacles. Organ-specific metabolic adaptation can help metastatic cancer cells overcome the obstacles faced when colonizing distant organs and establishing an organotropism phenotype [14]. 


\section{Bone}

Bone has a high mineral content, extreme hardness, high extracellular calcium concentration, a hypoxic microenvironment and acidic $\mathrm{pH}[44,45]$. The inorganic phase of bone is mainly composed of mineral hydroxyapatite (HA) crystals, while the bone matrix is rich in type I collagen, osteopontin and bone sialoprotein [45]. In addition, the bone matrix is also rich in a variety of cytokines and growth factors [45]. The bone microenvironment contains many types of cells, such as osteoblasts, osteoclasts, haematopoietic stem cells, adipocytes and immune cells [46]. Under normal conditions, osteoblasts and osteoclasts establish a dynamic balance between bone formation and decomposition [46]. Bone metastasis often occurs in prostate cancer, breast cancer and lung cancer. Among these processes, bone metastasis of prostate cancer usually presents an osteoblastic metastasis phenotype, while breast cancer and lung cancer often present an osteolytic metastasis phenotype [46]. Metastatic cells interact with osteoblasts and osteoclasts in the bone microenvironment to promote the release of growth factors in the bone matrix and thus promote the growth of the cancer cells at the site of the metastasis, forming a "vicious cycle" of bone metastasis [46].

The metabolic adaptation of bone metastatic cells is mainly related to the specific metabolites, oxygen content and various cell types in the bone microenvironment. In mouse models of breast cancer, cancer cells are more likely to metastasize to sites containing immature HA, such as smaller, incomplete, and non-oriented crystallized HA sites [47]. Breast microcalcifications are common in the primary site of breast cancer. Therefore, radiography of breast microcalcifications is commonly used in clinical screening for breast cancer. Breast microcalcifications can be divided into two types. Type I microcalcifications are mainly composed of calcium oxalate crystals, which are common in benign tumours [48]. Type II microcalcifications are mainly composed of HA and are common in benign or malignant tumours [48]. Microcalcification in the primary site of breast cancer is related to cell proliferation and migration, inflammation and matrix degradation [48]. Breast cancer cells may increase the intracellular calcium ion concentration through phagocytosis and the degradation of intracellular crystals, thereby exerting cancer-promoting effects [49]. In addition, previous studies have shown that there is a pre-selection mechanism for cancer metastasis. Because of similarities between the primary microenvironment and the secondary microenvironment, the propensity for bone metastasis may pre-exist in the primary cancer [13]. The existence of the pre-selection mechanism means that the primary tumour microenvironment can be used to predict the organ specificity of cancer metastasis and provide markers for early clinical diagnosis and treatment. In view of the presence of HA in the microcalcification area and bone metastases in breast cancer, predictions on the tendency of bone metastasis based on the existence and morphological structure of microcalcification in the primary site remain to be explored. Prostate cancer, breast cancer, and renal cell carcinoma with a tendency to metastasize to bone can sense the extracellular $\mathrm{Ca}^{2+}$ concentration through calcium-sensitive receptors to promote cell proliferation and migration [50-52]. Therefore, whether metastatic cancer cells can increase the extracellular $\mathrm{Ca}^{2+}$ concentration through phagocytosis and degradation to exert biological effects remains to be determined.

In the primary site, hypoxia is an important feature of the tumour microenvironment [53]. Similarly, the bone metastatic microenvironment is also a hypoxic environment [44]. Hypoxia and HIF-1 expression can promote breast cancer bone metastasis and induce osteolytic metastasis by inhibiting osteoblast differentiation and promoting osteoclast production [54]. Moreover, ERnegative breast cancer cells with hypoxia at the primary site can secrete lysyl oxidase to promote the formation of premetastatic niches in osteolytic bone [55], revealing the close relationship between hypoxia and bone metastasis. Hypoxia in the primary site can lead to the production of a large amount of lactic acid, causing a reduction in extracellular $\mathrm{pH}$ [53]. The bone metastatic microenvironment can also induce the formation of an extracellular acidic environment due to the combined actions of osteoclasts and bone metastatic cancer cells [56]. Therefore, studying the similarity of metabolic microenvironments of the primary site and the metastatic site is helpful for exploring the mechanism of organotropism.

In addition, the specific cellular metabolic interactions in the bone metastatic microenvironment are also related to bone-specific metastasis. Serine metabolism is very important for osteoclastogenesis [57]. Compared with breast cancer cells with weak bone metastasis activity, the expression of de novo serine synthesis enzymes, including PHGDH, PSAT1, and PSPH, is increased in breast cancer cells with high bone metastasis activity [58]. Serine can stimulate the formation of human osteoclasts and promote their osteolytic activity [58]. Therefore, breast cancer cells may promote the formation of osteoclasts through the de novo synthesis of serine to promote a vicious cycle. The lactate released by MDA-MB-231 cells through glycolysis can be taken up by osteoclasts to provide energy, enhance their ability to degrade bone matrix, and promote the formation of osteolytic metastasis [59]. Osteogenic cells can deliver $\mathrm{Ca}^{2+}$ to cancer cells through gap junctions and activate downstream calcium signalling pathways and mTOR signalling pathways to support 
the progression of bone metastasis [60]. In addition to osteoclasts and osteogenic cells, the metabolic interactions between bone marrow adipocytes and cancer cells can also promote cancer cells adaptation to the bone microenvironment. Bone metastatic prostate cancer cells can take up lipids from bone marrow adipocytes through fatty acid-binding protein (FABP) 4 to promote cancer growth and invasion [61-63]. Bone marrow adipocytes can also promote the activation of HIF- $1 \alpha$ in metastatic prostate cancer cells, resulting in metastatic cells acquisition of the Warburg effect phenotype [64]. In addition, primary cancer cells can also secrete exosomes to deliver pyruvate kinase $\mathrm{M} 2$ to bone marrow stromal cells (BMSCs) and upregulate CXCL12 of BMSCs in a HIF$1 \alpha$-dependent manner, forming a premetastatic niche for bone metastasis of prostate cancer [65].

In summary, the current studies on the metabolic adaptation of bone metastasis mainly focus on the roles of inorganic components and bone-specific cells. However, most of the effects of bone inorganic components on cancer has been characterized based on in vitro tests, and more in vivo tests are needed to prove that these effects truly occur. The understanding of the effects of bonespecific cells on cancer metabolism is still limited to the interaction between cancer cells and other cells. Thus, more studies are needed to demonstrate how multiple cellular synergies affect the metabolism of bone metastases. Because osteolytic metastasis can degrade not only the inorganic component HA in the bone matrix but also the organic component, studies should be taken to determine whether osteolytic metastasis cells can directly obtain organic nutrients from the matrix by promoting osteoclast function.

\section{Liver}

The liver is the metabolic centre, where liver cells complete most metabolic activities of the whole body to control substance and energy balances. The liver has a unique blood supply system composed of the hepatic artery and portal vein, which merge through the sinusoids and finally flow into the central vein [66]. Arterial blood from the hepatic artery is enriched with nutrients and oxygen, while venous blood from the portal vein contains food-derived substances such as lipid droplets and is deoxygenated [66]. Therefore, the liver has a hypoxic microenvironment. In addition, the liver microenvironment is composed of a variety of cells, including hepatocytes, hepatic stellate cells (HSCs), sinusoidal endothelial cells and many kinds of immune cells [67]. Liver metastasis often forms with breast cancer, melanoma and gastrointestinal cancer cells. The reason that the incidence of metastatic liver cancer is higher than that of primary liver cancer requires a two-part explanation. First, the special blood supply system of the liver and the high permeability of blood sinuses may provide appropriate secondary sites. Second, due to the natural tolerance of the liver to substances derived from intestinal microorganisms, an immune-tolerant environment is developed [68].

The metabolic adaptation of liver-specific metastatic cells is mainly related to competition for hepatic nutrients, the hypoxic environment, and the effects of intrahepatic cells. Metastatic liver cancer cells may compete with liver cells for nutrients needed for growth by acquiring metabolic capacity similar to that of health liver cells. Low-dose fructose is mainly metabolized by the small intestine, and high-dose fructose is mainly metabolized by colon microorganisms and the liver [69]. However, liver metastatic colon cancer cells can upregulate aldolase B via GATA6, thereby acquiring the ability to metabolize fructose and enhancing the proliferation ability of colon cancer cells [70]. A recent study showed that liver metastasis of colorectal cancer can induce epigenetic remodelling through enhancers or super enhancers, thereby causing the migrating colorectal cancer cells to lose their colorectum-specific transcription programme and acquire a liver-specific transcription programme [71]. In addition, this study also used the gene expression profiles of a large number of primary and metastatic cancers to show the universality of transcription characteristic elimination from primary cancer cells and transcription characteristics acquisition of secondary site cells [71]. More studies are needed to prove whether other types of metastatic cancer cells also acquire the transcriptional and metabolic characteristics of the metastatic site through epigenetic remodelling.

There is a hypoxic microenvironment in the liver that can easily lead to the depletion of ATP that causes metastatic cancer cells to die. Metastatic cancer cells in the liver from colorectal cancer can downregulate miR483-5p and miR-551a to upregulate the expression of a brain-type creatine kinase and secrete it into the liver metastatic microenvironment, phosphorylating creatine to produce phosphocreatine [72]. Subsequently, phosphocreatine is taken up by the metastasized colorectal cancer cells to supply intracellular ATP, allowing them to survive under hypoxic conditions [72]. A study on the metabolic reprogramming of multiple organ metastases of breast cancer found that compared with breast cancer at the primary site, breast cancer cells that have metastasized to the liver, bone or lung show increased glycolysis and tricarboxylic acid cycle activity levels [73]. However, compared with that of bone and lung metastasis, the expression of HIF- $1 \alpha$ and HIF- $1 \alpha$ target PDK1 expression are at a higher level in liver cancer metastasis, resulting in stronger downstream glycolytic activity; however, oxidation phosphorylation and glutamine metabolism 
are weaker in the liver, which promotes the adaptation of cancer cells to the hypoxic environment in the liver [73]. Therefore, the hypoxic microenvironment in the liver forces metastatic cancer cells to undergo greater energy metabolism and enhances the characteristics of the Warburg effect.

Intrahepatic cells can also change the metabolic characteristics of liver metastases. Under normal physiological conditions, HSCs are in a resting state. However, upon triggered inflammation, HSCs are activated to become hepatic myofibroblasts (HMFs). The expression level of succinate dehydrogenase B (SDHB) is higher and the OXPHOS activity is stronger when pancreatic ductal epithelial cells (PDECs) were cocultured with HSCs than cocultured with HMFs. [74]. Knocking down SDHB can enhance cell proliferation and increase CSC characteristics [74]. Consistently, liver micrometastases (representative of a non-inflammatory environment) in KPC mice with pancreatic cancer exhibited higher expression of SDHB and lower expression of the CSC marker nestin than liver macrometastases (representative of a highly inflammatory environment) [74]. This finding shows that the activation level of HSCs and the inflammatory state of the liver can affect the metabolic state, proliferation ability and stem cell characteristics of PDECs. More evidence is needed to prove that other types of cells in the liver can affect the metabolic characteristics of liver metastases.

In summary, liver metastatic cells can acquire the specific metabolic ability of the liver and adapt to the hypoxic environment. The metabolic ability of liver metastatic cells can also be affected by other cells in the liver. In fact, there are other specific metabolic features of the liver, such as ketone body metabolism, enterohepatic circulation of bile acid, and ammonia metabolism, that may change the metabolic behaviour of cancer cells. For example, the aforementioned liver cancer cells can decompose ketone bodies to obtain substrates for energy metabolism [19]. Therefore, more studies are needed to demonstrate that other metabolic characteristics of liver cells can influence the metabolic behaviour of cancer cells that have metastasized to the liver.

\section{Lung}

Lung metastasis often follows breast cancer, melanoma, and colon cancer [75]. The lung is the respiratory organ through which oxygen is inhaled and carbon dioxide is exhaled. Therefore, in contrast to the hypoxic environment of the bone and liver, the lung contains high oxygen levels, and cancer cells need to overcome the stress caused by oxidative damage to colonize in the lung. The abundant capillary network in the lung is conducive to cell adhesion and metastasis. However, the capillary endothelial cells are tightly connected, and therefore, cancer cells need to overcome the capillary barrier to colonize. There are many types of cells in the lung, including type I alveolar epithelial cells, type II alveolar epithelial cells, endothelial cells, fibroblasts, and various types of immune cells [75]. Furthermore, in addition to its respiration function, the lung also has many metabolic functions. While the lung plays a prominent role in lipid metabolism and the synthesis of pulmonary surfactant; on the other hand, it also synthesizes a variety of vasoactive substances, including amines, prostaglandins and peptides [76].

Currently, the metabolic adaptation of lung-specific metastasis mainly focuses on mitochondrial metabolism, antioxidant programmes, and the role of some metabolites or metabolic enzymes. Due to the oxygenrich microenvironment in the lungs, metastasizing cancer cells can rewire their metabolism from glycolysis to OXPHOS. A recent study used a breast cancer PDX model and single cell transcriptome sequencing technology to prove that lung and lymph node micrometastases exhibit high levels of OXPHOS activity [77]. In contrast, primary breast cancer cells show upregulated glycolytic activity [77]. This conclusion was also verified by flow cytometry and metabolomics [77]. Mitochondrial complex $\mathrm{V}$ inhibitor oligomycin can be used to inhibit breast cancer OXPHOS and lung metastasis effectively but has no effect on primary breast cancer [77], indicating that OXPHOS has a profound targeting effect on lung metastasis, which also suggests that drugs targeting the mitochondrial electron transport chain can be used to target lung metastases. Peroxisome proliferation-activated receptor coactivator 1 alpha $(\mathrm{PGC}-1 \alpha)$ is a core regulator of mitochondrial energy production and oxidative metabolism, and its expression is often altered during cancer metastasis [78]. However, the specific mechanism of PGC- $1 \alpha$ in cancer metastasis remains controversial. A study found that CTCs can increase the rate of mitochondrial OXPHOS, biosynthesis and oxygen consumption by upregulating PGC- $1 \alpha$ to promote subsequent lung metastasis [79]. Silencing PGC-1 $\alpha$ slows lung metastasis but does not affect primary cancer growth or the epithelial-mesenchymal transition (EMT) [79]. However, another study found no significant effect of the OXPHOS inhibitor metformin on metastasis in mice injected with breast cancer cells that highly express PGC-1 $\alpha$ [80]. In contrast to the mechanism by which PGC-1 $\alpha$ upregulates OXPHOS, this study indicated that PGC- $1 \alpha$ enhances global energy metabolism flexibility of breast cancer cells, thereby producing resistance to bioenergy interference drugs such as metformin [80]. Therefore, the relationship between PGC-1 $\alpha$ and cancer metastasis needs to be further studied. 
Oxygen not only changes the energy metabolism of cancer cells but also exposes cancer cells to oxidative stress [81]. Therefore, antioxidant programmes are required in lung metastatic cancer cells. Peroxiredoxin-2 can promote breast cancer metastasis to the lung by regulating oxidative stress, and silencing peroxiredoxin-2 can inhibit breast cancer lung metastasis by inducing oxidative damage [82]. Flura-seq, a highly sensitive in situ sequencing technology, and mouse PDX breast cancer models were used in a study showing that compared with breast fat pad and brain micrometastases, lung micrometastases induce mitochondrial electron transport complex I, oxidative stress and antioxidation programmes [83]. This study confirmed an increase in lung metastasis-specific oxidative stress and the upregulation of antioxidant programmes in clinical samples [83]. In fact, at multiple stages of cancer metastasis, cancer cells must overcome oxidative stress while breaking away from the extracellular matrix, living in the circulatory system, and colonizing [79, 84, 85]. Therefore, the ability of cancer cells to adapt to oxidative stress may be acquired before they metastasize to the lung.

Many metabolites or metabolic enzymes can influence lung metastasis through different mechanisms. Pyruvate carboxylase (PC) catalyses pyruvate to produce oxaloacetate, which can then be used for gluconeogenesis or to replenish the TCA cycle. Lung metastatic breast cancer depends on PC. PC-deprived breast cancer cells show a decrease in glycolytic capacity and oxygen consumption rate and an increase in sensitivity to oxidative stress [86]. Through ${ }^{13} \mathrm{C}$ tracing analysis, it was found that, compared with primary breast cancer, the concentration of mitochondrial pyruvate in lung metastatic breast cancer increases, thereby promoting PC-dependent replenishment through enzymatic kinetics [87]. Surprisingly, the growth of primary NSCLC also depends on PC [40, 88]. Therefore, factors in the lung microenvironment may enable both primary and metastatic cells to acquire a PCdependent phenotype. However, the factors in the lung microenvironment that promote cancer cell acquisiton of a PC-dependent phenotype remain to be explored. Pyruvate can also be directly converted into $\alpha$-ketoglutarate by alanine aminotransferase [89]. Subsequently, $\alpha$-ketoglutarate activates $\mathrm{P} 4 \mathrm{HA}$ through enzymatic kinetic metabolism, promotes collagen hydroxylation, extracellular matrix remodelling, and the growth of lung metastatic breast cancer [89]. Fatty acid metabolism can also affect ability of cancers to metastasize the lung. High expression of AKR1B10 in breast cancer cells show reduced glycolytic activity and dependence on glucose and enhanced fatty acid oxidation (FAO) [90]. In threedimensional cancer spheroids formed in vitro and cancer metastases formed in vivo, FAO inhibitors blocked the metastasis of AKR1B10 $0^{\text {High }}$ cancer cells but did not affect AKR1B10 ${ }^{\text {Low }}$ cancer cells [90]. Further analysis confirmed that AKR1B10 can limit the side effects caused by of oxidative stress, thereby maintaining FAO in lung metastatic breast cancer [90]. Proline dehydrogenase catalyses the catabolism of proline. In a mouse model of lung metastasis, the expression of proline dehydrogenase in the lung metastatic cells was higher than primary cancer cells [91]. Inhibition of proline dehydrogenase effectively reduced the formation of lung metastasis in these mice [91]. Another study found that the bioavailability of asparagine affected the metastatic potential of breast cancer [92]. Knockdown of asparagine synthetase, L-asparaginase treatment or direct restriction of asparagine in the diet can reduce lung metastasis by breast cancer cells without affecting primary cancer growth [92]. Increasing dietary asparagine or enhancing the expression of asparagine synthetase can promote breast cancer metastasis to the lung [92]. Therefore, this study also reveals that the use of dietary therapy can be explored from the perspective of cancer metabolism to reduce the incidence of clinical cancer metastasis.

In summary, metastatic cancer cells in the lung can adjust their energy metabolism to aerobic oxidation and adapt to the high oxidative stress environment, and they can be affected by certain metabolites and metabolic enzymes. However, it is still unclear how the metabolic capacity of cells in the lung and the inherent metabolic functions of the lung affect the metabolism of lung metastases. In addition, because of the tight junctions of capillary endothelial cells in the lungs, metastatic breast cancer cells tend to show increased expression of prostaglandin-endoperoxide synthase 2 (PTGS2, also known as COX2) [93]. Prostaglandin, a product of PTGS2, can enhance capillary permeability. Cancer metabolism enhancement of lung capillary permeability to promote cell migration across the endothelium remains to be studied.

\section{Brain}

The brain is protected by the blood-brain barrier and the blood-cerebrospinal fluid barrier forming a relatively isolated environment. Although these barriers can protect the brain from external harmful substances, they also block some therapeutic drugs from entering the brain [94]. Neurons are the functional units of the nervous system. According to the neurotransmitters released from their nerve endings, neurons can be classified into glutamatergic neurons and gamma-aminobutyric neurons. Therefore, cancer cells that can use these neurotransmitters for processes such as energy synthesis, biosynthesis, and antioxidative stress have tremendous survival and proliferation advantages. Brain metastasis often 
occurs following lung cancer, breast cancer or melanoma. According to the location of metastasis, secondary brain cancer be divided into brain parenchymal metastasis and leptomeningeal metastasis [94]. The latter is a cancer that has metastasized to the subarachnoid space. The metabolic microenvironments of the brain parenchyma and the subarachnoid space are completely different. The brain parenchyma is composed of many types of cells, including neurons, astrocytes, oligodendrocytes, which consume a large amount of oxygen and mainly procure a sufficient amount of fuel from glucose or ketone bodies produced in the liver to undergo oxidative metabolism [95]. Thus, the brain has the characteristics of low energy reserves, high energy supply and high energy consumption. The subarachnoid space is filled with cerebrospinal fluid, which is notably hypoxic and nutrient deficient [95]. Different metabolic microenvironments may also lead to different metabolic characteristics of brain metastases.

Currently, the metabolic adaptations necessary for brain-specific metastasis is mainly related to brain-specific metabolites and the interaction between brain cells and tumour cells. Proteomics analyses have revealed that breast cancer cells metastasized to the brain tend to enhance the expression of metabolic enzymes involved in glycolysis, TCA cycle, OXPHOS, pentose phosphate pathway and glutathione system. These findings indicate that brain metastatic breast cancer cells may, on the one hand, obtain energy through the oxidative metabolism of glucose and, on the other hand, respond to oxidative stress by enhancing the alternative glucose metabolism pathway and maintaining cell redox homeostasis, thus gaining an advantage in survival and growth in the brain microenvironment [96]. Comparing the gene expression profiles of brain metastases and extracerebral metastases of melanoma, the metastatic melanomas in the brain are enriched in the OXPHOS pathway [97]. By comparing OXPHOS gene expression, the metabolome and metabolic pathway activity in intracranial and subcutaneous xenograft melanoma mice, the conclusion that OXPHOS activity is increased in brain metastatic melanoma was also confirmed [97]. OXPHOS inhibitors can improve the survival rate of intracranial melanoma xenograft mice, resistant to MAPK inhibitors and inhibit brain metastasis in spontaneous brain metastasis of melanoma in mouse models [97]. Similarly, a study that infused ${ }^{13} \mathrm{C}$-labelled glucose during surgical resection of brain gliomas and brain metastases and then used ${ }^{13} \mathrm{C}$ NMR spectroscopy to test related metabolites found that brain metastasis and primary brain tumour metabolism are very similar. These cells mainly used glucose for mitochondrial oxidation and for the production of lactic acid, alanine, glutamic acid, glutamine and glycine [98]. These findings show that glycolysis, the TCA cycle, OXPHOS and some nonessential amino acid synthesis pathway activity are enhanced in glioma and brain metastatic tumours. However, the study also found that less than $50 \%$ of the acetylCoA pool is derived from glucose in the blood, indicating that other substances supply the energy metabolism of these glioma and brain metastatic cells [98]. In addition to glucose metabolism, lipid metabolism has an impact on brain metastasis. The FABP family is involved in the uptake, transport and metabolism of fatty acids. High expression of FABP7 is associated with poor prognosis and a high incidence of brain metastasis in breast cancer patients [99]. Through in vivo and in vitro experiments, researchers discovered that FABP7 can promote HER2 + breast cancer cells adaptation to the brain microenvironment by supporting the glycolytic phenotype and lipid droplet storage [99]. Amino acid metabolism can also affect brain metastasis. Brain metastatic breast cancer cells can use gluconeogenesis and branched chain amino acid oxidation to promote the survival and growth of breast cancer in the brain microenvironment [100]. Acetate metabolism also promotes brain metastases. Both primary brain tumours and various types of brain metastatic cells can oxidize acetate to meet their energy requirements [43]. Therefore, the glucose metabolism, lipid metabolism, amino acid metabolism and acetic acid metabolism of brain metastatic tumours undergo different degrees of changes, indicating that brain metastatic tumours seem to have extraordinary metabolic flexibility, facilitating the adaptation of these cells to the complex and unique brain microenvironment.

The most common cell type in the brain is the neuron. Neurons and cancer cells can communicate through neurotransmitters to promote the colonization of brain metastases. Gamma-aminobutyrate (GABA) is a common neurotransmitter in the brain. Brain tumour samples obtained during neurosurgery for HER2 + and triple-negative breast cancer, revealed that brain metastasis of breast cancer has GABAergic characteristics; that is, the brain metastatic cells have high expression of GABA-related proteins, including $\mathrm{GABA}_{\mathrm{A}}$ receptors, GABA transporters, GABA transaminase and glutamate decarboxylase [101]. Further in vitro studies found that brain metastatic breast cancer cells undergo GABA catabolism to increase NADH levels, which indicates metastatic breast cancer cells with proliferation advantages in the brain [101]. Glutamate is also a common neurotransmitter in the brain, and one of its receptors is the $\mathrm{N}$-methyl-D-aspartate receptor (NMDAR). In glutaminergic synapses, glutamate released by presynaptic neurons is rapidly absorbed by postsynaptic neurons and astrocytes around synapses, which not only ensures the timeliness of synaptic conduction but also prevents the toxic effect of high extracellular concentrations of 
glutamate on nerve cells [102]. A recent study found that breast cancer cells can replace astrocytes and form pseudo-tripartite synapses with glutamatergic neuron cells [103]. Metastatic cells can use glutamate released by neuronal cells to activate NMDAR receptors, thereby promoting brain metastasis [103]. In addition to neurons, other cells in the brain can also metabolically interact with brain metastatic cells through different mechanisms. Astrocytes can sequester calcium ions in the cytoplasm of melanoma cells through gap junctions and promote the chemotherapy resistance of melanoma cells in brain metastases [104]. Brain metastatic tumour cells can also deliver the second messenger cGAMP to astrocytes through gap junctions, activate the STING signalling pathway in astrocytes, and produce the inflammatory factors IFN $\alpha$ and TNF. Subsequently, inflammatory factors activate the STAT1 and NF- $\mathrm{kB}$ signalling pathways of brain metastatic cells through paracrine signalling to promote tumour cell growth and drug resistance [105]. Therefore, brain metastatic cells can promote the process of colonization through metabolic interactions with brain cells.

In summary, brain metastatic cells have a high degree of metabolic reprogramming, and they can also interact with neurons and astrocytes through neurotransmitters and gap junctions. However, the metabolic interactions between other types of cells and brain metastatic cells remain to be studied, and the differences in the metabolism of parenchymal brain metastasis and leptomeningeal metastasis also needs to be studied. In addition, similar to breast cancer cells with a tendency for lung metastasis, the expression of PTGS2 in breast cancer cells with a tendency for brain metastasis is also increased [106], suggesting that lung and brain metastatic breast cancer may pass through tight capillary connections through similar tumour metabolic mechanisms. In fact, a study found that PTGS2 is involved in the formation of cerebrospinal fluid tumour cells in brain metastatic breast cancer, which also indicates that PTGS2 is closely related to brain metastasis [107].

\section{Others}

Approximately $80 \%$ of serous ovarian cancer metastasizes to the omentum. The omentum is rich in adipocytes and stores a large amount of lipids, which can promote omentum-specific metastasis of ovarian cancer [108]. Through the coculture model of adipocytes and ovarian cancer cells, adipocytes were found to transport lipids to ovarian cancer cells and promote cancer cell growth in vivo and in vitro [109]. Further studies revealed that the coculture model can induce lipid decomposition of adipocytes, promote $\beta$-oxidation of cancer cells, and enhance the acquisition of rich sources of energy by cancer cells [109]. In a comparison of primary ovarian cancer and omental metastasis, FABP4 was found to be upregulated in omental metastatic ovarian cancer and is located at the interface between adipocytes and cancer cells [109]. FABP4-deficient mice with ovarian cancer have reduced omental metastasis, confirming that adipocyte-derived lipids play important roles in the omental metastasis of ovarian cancer [109]. Another study found that in a coculture model consisting of adipocytes and ovarian cancer cells, the expression of the fatty acid receptor $\mathrm{CD} 36$ on the membrane of the ovarian cancer cells is increased, promoting the uptake of fatty acids by ovarian cancer cells [110]. In addition, CD36 plays a role in multiple processes of ovarian cancer metastasis to the omentum, including adhesion, invasion, migration and non-anchored growth [110]. Therefore, inhibition of CD36 can effectively inhibit ovarian cancer metastasis. Secreted protein acidic and rich in cysteine (SPARC) can inhibit omental metastasis of ovarian cancer by inhibiting the interaction between ovarian cancer cells and adipocytes, thereby inhibiting the phenotypic plasticity of omental adipocytes and metabolic reprogramming [111]. Among the inhibitory mechanisms, the effect of SPARC on metabolism is mainly to inhibit the metabolic reprogramming of adipocytes and ovarian cancer cells, inhibit adipocyte differentiation, and inhibit adipocytes from acquiring cancer-related phenotypes [111]. Compared with its level in primary ovarian cancer, salt-induced kinase 2 (SIK2) is highly expressed in lipidrich metastases [112]. Adipocytes can activate the phosphorylation and activation of SIK2 in ovarian cancer cells in a calcium-dependent manner. On the one hand, activated SIK2 can activate the PI3K-AKT signalling pathway to promote cancer cell proliferation and survival; on the other hand, it can inhibit acetyl-coenzyme A carboxylase in combination with AMPK phosphorylation, increasing the expression of carnitine palmitoyl transferase 1 and activating FAO, thereby promoting omental metastasis of ovarian cancer [112]. In addition to lipid metabolism, omental adipose stromal cells can induce increased nitric oxide synthesis in ovarian and endometrial cancer cells, thereby promoting cancer cell proliferation [113]. Nitric oxide is catalysed from arginine via nitric oxide synthase, and citrulline is also produced. Research using a model of cocultured omental adipose stromal cells and cancer cells found that the cancer cells absorb arginine secreted by the omental adipose stromal cells and then secrete citrulline into the microenvironment [113]. Citrulline can increase adipogenesis in omental adipose stromal cells [113]. Further studies found that the increased nitric oxide synthesis in cancer cells induced by omental adipose stromal cells can upregulate glycolysis, reduce mitochondrial respiration, and reduce oxidative stress [113]. 
In addition to adipocytes, cancer-associated fibroblasts (CAFs) can also affect omental metastasis of ovarian cancer through cancer metabolism. With a model of cocultured omentum-derived CAFs and ovarian cancer cells, it was found that the activation of $\mathrm{p} 38 \alpha$ MAPK in the CAFs promote the phosphorylation and activation of the glycogen metabolism enzyme glucose phosphate mutase 1 under normoxic conditions in the cancer cells [114]. Subsequently, the glycogenolysis of the cancer cells is increased, which supplies glycolysis and promotes cancer cell proliferation, invasion and metastasis [114]. Further studies using in vivo models showed that the depletion of p38 $\alpha$ in CAFs and the inhibition of glycogenolysis in cancer cells can reduce omental metastasis [114]. Therefore, the propensity for omentum metastasis is related to multiple cell types and multiple metabolic pathways, which is of great significance to our understanding of the propensity for cancer metastasis.

Lymph node metastasis is often used to predict the risk of distant metastasis and death. It is also closely related to the prognosis of clinical patients and the choice of treatment method. A number of studies have shown that lymph node metastasis can be used as a foothold for distant metastasis $[115,116]$. However, some studies have shown that lymph node metastasis is not the only way for distant metastasis [117]. Metabolic reprogramming studies of lymph node metastatic tumours mainly focus on lipid metabolism. In melanoma and breast cancer cells metastasized to lymph nodes, accumulated bile acid activates YAP through the vitamin D receptor, which leads to FAO activation of the cancer cells and facilities their adaptation to the lymph node microenvironment [118]. The long-chain noncoding RNA LNMICC recruits nuclear factor NPM1 to the promoter of FABP5 to reprogramme fatty acid metabolism and then promotes cervical cancer cell metastasis to lymph nodes through the EMT and VEGF-C-mediated lymphangiogenesis [119]. Therefore, lipid metabolism-targeted drugs may inhibit lymph node metastasis, thereby delaying cancer progression. In fact, the use of the FAO inhibitor etomoxir, a hypoglycemic agent, can effectively inhibit lymph node metastasis [118].

\section{Conclusions \\ Driving effects of the metabolic microenvironment on cancer metastasis}

Increasing evidence shows that the metabolic microenvironment plays important roles in driving metastasis. On the one hand, as mentioned above, cancer cells need to adapt to the metabolic microenvironment of the secondary environment to survive and proliferate (Fig. 2). On the other hand, cancer cells that cannot adapt to the primary metabolic microenvironment may leave the original site and colonize a microenvironment that better suited to their metabolic needs. Hypoxic lung cancer cells leave the oxygen-rich lung microenvironment and metastasize to hypoxic environments [120]. Liver cancer cells with vigorous mitochondrial metabolism can leave the hypoxic liver microenvironment and metastasize to the oxygen-rich lung microenvironment [121]. Therefore, studying the specific metabolic characteristics of various tissues and organs will help us further understand the reasons for cancer metastasis to secondary sites. In addition, designing drugs based on the metabolic characteristics of various tissues and organs will enable the targeting of metastasis from a new perspective.

\section{Process of mutual adaptation between seeds and the soil} While paying attention to the different metabolic microenvironments of different metastatic organs, we need to also pay attention to the dynamic changes of the metabolic microenvironment of the metastatic organ. On the one hand, primary tumours can transform the remote metabolic microenvironment of secondary organs through different mechanisms, which is the process of forming premetastatic niches. On the other hand, as the cancer reaches the secondary organs and changes from a micrometastasis to a macrometastasis, the microenvironment of the secondary organs is constantly modified. Therefore, the metabolic adaptation process of organspecific metastasis is not merely a process in which the cancer cells constantly change; it is also a process in which cancer cells and metastatic organs continuously adapt, influence and change each other.

\footnotetext{
(See figure on next page.)

Fig. 2 Metabolic adaptation mechanism of metastatic organotropism. Cancers that metastasize to bone (a), liver (b), lung (c) and brain (d), omentum, and lymph nodes need to adapt to different metabolic microenvironments to survive and grow at a distant site. Metastasizing cancer cells need to adapt to the metabolic microenvironments of the secondary organ, which mainly includes changes in energy and nutrient sources, organ-specific metabolites, pH, the degree of hypoxia, and the metabolic interactions between organ-specific cells and cancer cells. HA hydroxyapatite, Ser serine, Lact lactate, FA fatty acid, BMSCs bone marrow stromal cells, ALDOB aldolase B, HSCs hepatic stellate cells; HMFs hepatic myofibroblasts, OXPHOS oxidative phosphorylation, CKB brain-type creatine kinase, FAO fatty acid oxidation, PGC-1a peroxisome proliferation-activated receptor co-activator 1 alpha; $P R D X 2$ peroxiredoxin-2, $P R O D H$ proline dehydrogenase, $A S N S$ asparagine synthetase, $P C$ pyruvate carboxylase, ALT alanine aminotransferase, $a-K G$ a-ketoglutarate, ECM extracellular matrix, GABA gamma-aminobutyrate, $P P P$ pentose phosphate pathway, Glu glutamate, BCAA branched chain amino acid
} 
a

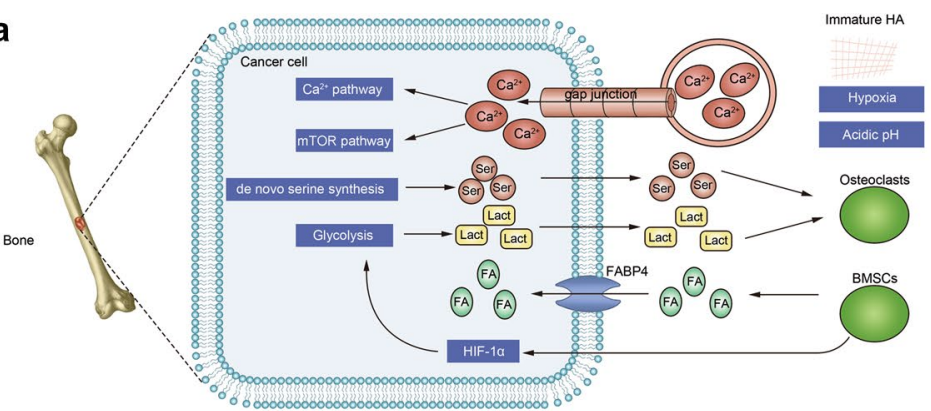

b
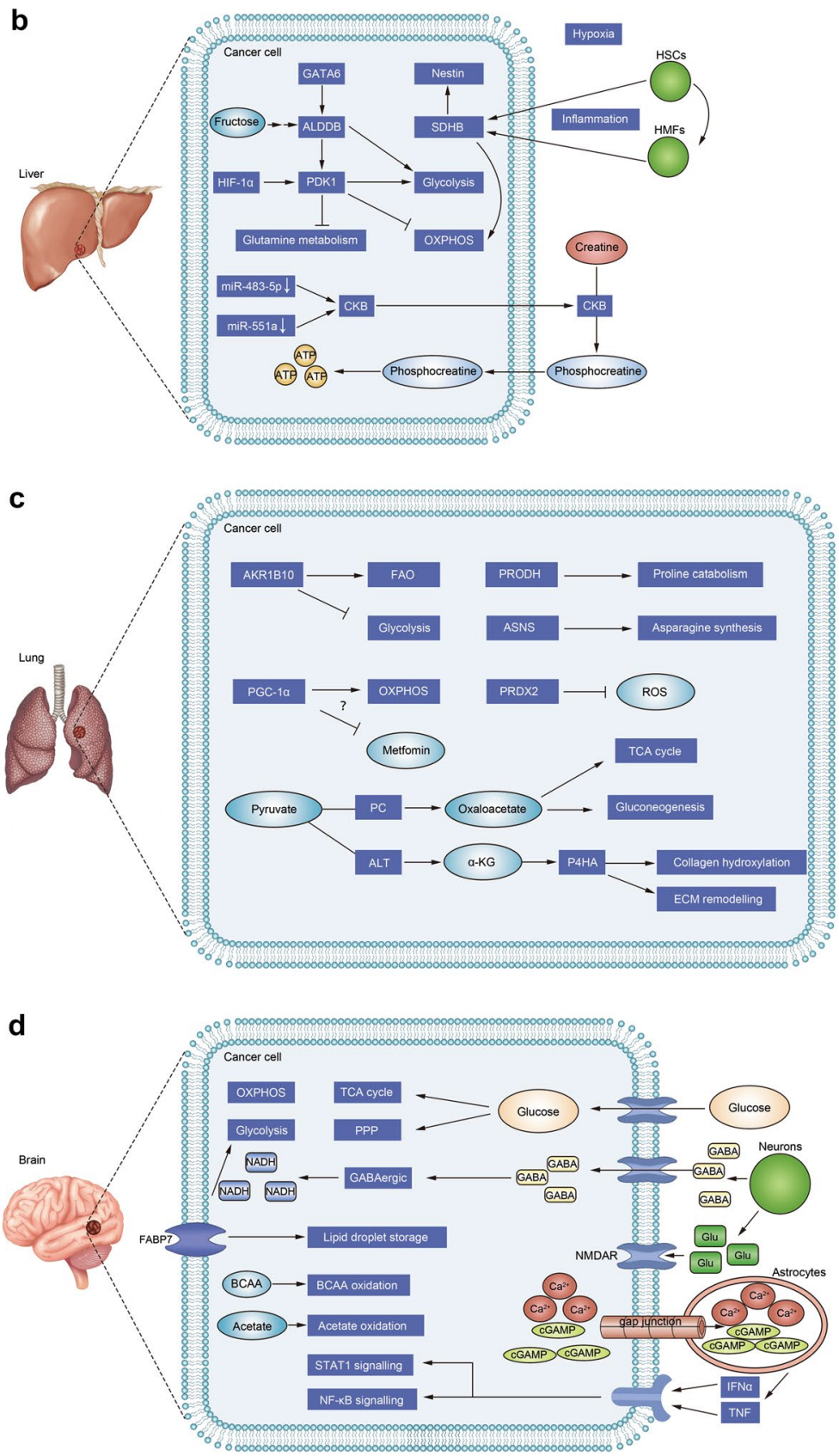


\section{Selection or adaptation?}

Is the metabolic adaptation mechanism of metastatic cells the result of selection or adaptation? If it is the result of selection, then the driving factors of the metabolic phenotype likely originate from mutations, copy number variations and other genomic changes. Therefore, we may be able to identify the driving genes critical for metabolic phenotype changes in metastatic cancer cells through large-scale metastatic cancer genome resequencing. If the metabolic adaptation mechanism is the result of adaptation, than the factors driving the acquisition of the metabolic phenotype are reversible mechanisms, and are derived from the environment, likely in relation to epigenetic mechanisms. Therefore, in the process of organspecific metastasis, changes in the environment may induce epigenetic changes, leading to changes in metabolism. Metabolism can also affect epigenetic modifications [17], thereby further promoting organ-specific metastasis. Because epigenetic changes are fast and reversible compared to mutations, they may be more flexible and common.

\section{Treating CTCs as a form of circulatory system metastasis}

When studying the metabolic adaptation mechanism of metastasis, we can regard CTCs as a form of circulatory system metastasis and explore how cancer cells match the metabolic microenvironment of the circulatory system. After non-transformed cells detach from the extracellular matrix of the primary site, they often undergo increased intracellular ROS and anoikis. Cancer cells can resist this process by enhancing the intracellular antioxidant programme [122]. Therefore, the current research with metabolic models of CTCs mainly focuses on antioxidant metabolism. However, treating CTCs from the perspective of metabolic adaptation, we may discover more possible research directions, such as the influence of the difference in arterial and venous oxygen or nutrient content in the circulatory system, and the influence of metabolic interactions between various cells in the circulatory system and cancer cells.

\section{Application of emerging technologies}

The application of emerging technologies can produce more in-depth insights into the metabolic adaptation mechanism of organ-specific metastasis. Single-cell transcriptome sequencing combined with PDX models can be used to study rare cell subpopulations during cancer metastasis. For example, studies on the micrometastatic clones formed by DTCs may reveal a more refined metastatic process [77]. Using in situ transcriptome sequencing technology combined with a PDX model not only enables study into the changes in the expression of metabolic enzymes but also the spatial location information of metastatic cells [83] to gain understanding into spatially specific metabolic reprogramming during metastasis. Moreover, this technology is helpful for studying the metabolic differences of cancer cells in different environments within the same primary or metastatic tumour. Metabolomics and metabolic flux analysis, the two major metabolic high-throughput analysis methods, may significantly enhance the overall capabilities for comprehensive research in this field. The combination of transcriptomics, proteomics, metabolomics and other multi-omics technologies will also reveal the mechanisms of cancer metastasis and metabolic reprogramming on multiple levels.

\section{Clinical significance of metastatic adaptation mechanisms}

According to the metabolic adaptation mechanism of cancer metastasis, different cancer cells that metastasize to the same organ have similar metabolic characteristics. Therefore, designing therapeutic targets for these metabolic characteristics may provide new ideas for the prevention and treatment of cancer metastasis. Since liver metastasis is usually more active in anaerobic glycolysis, we can try to use respiratory chain inhibitors to prevent the process of lung metastasis. By contrast, we can also try to use glycolysis inhibitors to interfere liver metastasis which has an active anaerobic glycolysis mode. In addition to targeting the metabolic process of cancer cells, it is also possible to try to change the inherent metabolic characteristics of certain organs with a high frequency of metastasis, making it difficult for cancer cells to adapt to corresponding organs. The bone matrix degradation within the metastatic microenvironment plays a vital role in osteolytic metastatic cancer. Therefore, inhibiting this process may hinder bone metastasis. The local acidic environment of liver and bone may have a certain impact on the adaptability of metastatic cells. As a result, adjusting the $\mathrm{pH}$ of local organs through oral administration or local addition has great potential for the treatment of metastasis. In fact, existing studies have found that bicarbonate can markedly enhance the anticancer activity of transarterial chemoembolization [123]. In the terminal stage of clinical cancer patients, cancer cells mostly pass blood or lymphatic vessels to reach multiple organs throughout the body. Targeting circulatory or lymphatic metastasis may be able to prevent or inhibit this deadly process. Hence, we can try to use hemofiltration or other devices to adjust the concentration of some metastasisspecific nutrients in these vessels, thereby inhibiting the process of multiorgan invasion.

\section{Abbreviations}

CTCs: Circulating tumour cells; DTCs: Disseminated tumour cells; OXPHOS: Oxidative phosphorylation; CP: Carbamoyl phosphate; NSCLC: Non-small cell lung 
cancer; CPS: Carbamoyl phosphate synthase; UMPS: Uridine monophosphate synthase; HA: Hydroxyapatite; FABP: Fatty acid-binding protein; BMSCs: Bone marrow stromal cells; HSCs: Hepatic stellate cells; HMFs: Hepatic myofibroblasts; SDHB: Succinate dehydrogenase B; PDECs: Pancreatic ductal epithelial cells; PGC-1a: Peroxisome proliferation-activated receptor co-activator 1 alpha; EMT: Epithelial-mesenchymal transition; PC: Pyruvate carboxylase; FAO: Fatty acid oxidation; PTGS2: Prostaglandin-endoperoxide synthase 2; GABA: Gamma-aminobutyrate; NMDAR: N-methyl-D aspartate receptor; SPARC: Secreted protein acidic and rich in cysteine; SIK2: Salt-induced kinase 2; and CAFs: Cancer-associated fibroblasts.

\section{Acknowledgements}

The authors would like to thank Mrs. Shuhua Zhang and Mr. Yudi Yao for their insightful comments during their review of this manuscript.

\section{Authors' contributions}

CW carried out the primary literature search and drafted the manuscript; DL revised the manuscript. All authors read and approved the final manuscript.

\section{Funding}

This work was supported by grants from the National Natural Science Foundation of China, nos. 81560464 and 31960152 (DL) and Nanchang University National College Students Innovation and Entrepreneurship Training Program, nos. $2020 \mathrm{CX} 270$ (CW).

\section{Availability of data and materials}

Not applicable.

\section{Declarations}

Ethics approval and consent to participate

Not applicable.

\section{Consent for publication}

Not applicable.

\section{Competing interests}

Chao Wang and Daya Luo declare that they have no conflict of interest. This article does not contain any studies with human or animal subjects performed by any of the authors.

\section{Author details}

'School of Basic Medical Sciences, Nanchang University, Nanchang 330006, China. ${ }^{2}$ Department of Biochemistry and Molecular Biology, School of Basic Medical Sciences, Nanchang University, Nanchang 330006, China.

\section{Received: 13 December 2020 Accepted: 19 April 2021}

Published online: 29 April 2021

\section{References}

1. Hanahan D, Weinberg RA. Hallmarks of cancer: the next generation. Cell. 2011;144(5):646-74.

2. Lambert AW, Pattabiraman DR, Weinberg RA. Emerging biological principles of metastasis. Cell. 2017;168(4):670-91.

3. Obenauf AC, Massague J. Surviving at a distance: organ-specific metastasis. Trends Cancer. 2015;1(1):76-91.

4. Liu Q, Zhang H, Jiang X, Qian C, Liu Z, Luo D. Factors involved in cancer metastasis: a better understanding to "seed and soil" hypothesis. Mol Cancer. 2017;16(1):176.

5. Gandaglia G, Karakiewicz PI, Briganti A, Passoni NM, Schiffmann J, Trudeau V, Graefen M, Montorsi F, Sun M. Impact of the site of metastases on survival in patients with metastatic prostate cancer. Eur Urol. 2015;68(2):325-34.

6. Yang J, Manson DK, Marr BP, Carvajal RD. Treatment of uveal melanoma: where are we now? Ther Adv Med Oncol. 2018;10:1758834018757175.

7. Liu Q, Zhang R, Michalski CW, Liu B, Liao Q, Kleeff J. Surgery for synchronous and metachronous single-organ metastasis of pancreatic cancer: a SEER database analysis and systematic literature review. Sci Rep. 2020;10(1):4444.

8. Kennecke H, Yerushalmi R, Woods R, Cheang MC, Voduc D, Speers CH, Nielsen TO, Gelmon K. Metastatic behavior of breast cancer subtypes. J Clin Oncol. 2010;28(20):3271-7.

9. Wu Q, Li J, Zhu S, Wu J, Chen C, Liu Q, Wei W, Zhang Y, Sun S. Breast cancer subtypes predict the preferential site of distant metastases: a SEER based study. Oncotarget. 2017;8(17):27990-6.

10. Chen W, Hoffmann AD, Liu H, Liu X. Organotropism: new insights into molecular mechanisms of breast cancer metastasis. NPJ Precis Oncol. 2018;2(1):4.

11. Urosevic J, Garcia-Albeniz X, Planet E, Real S, Cespedes MV, Guiu M, Fernandez E, Bellmunt A, Gawrzak S, Pavlovic M, et al. Colon cancer cells colonize the lung from established liver metastases through p38 MAPK signalling and PTHLH. Nat Cell Biol. 2014;16(7):685-94.

12. Nguyen DX, Bos PD, Massague J. Metastasis: from dissemination to organ-specific colonization. Nat Rev Cancer. 2009;9(4):274-84.

13. Gao Y, Bado I, Wang H, Zhang W, Rosen JM, Zhang XH. Metastasis organotropism: redefining the congenial soil. Dev Cell. 2019:49(3):375-91.

14. Schild T, Low V, Blenis J, Gomes AP. Unique metabolic adaptations dictate distal organ-specific metastatic colonization. Cancer Cell. 2018;33(3):347-54

15. DeBerardinis RJ, Chandel NS. Fundamentals of cancer metabolism. Sci Adv. 2016;2(5):e1600200.

16. Koppenol WH, Bounds PL, Dang CV. Otto Warburg's contributions to current concepts of cancer metabolism. Nat Rev Cancer. 2011;11(5):325-37.

17. Pavlova NN, Thompson CB. The emerging hallmarks of cancer metabolism. Cell Metab. 2016;23(1):27-47.

18. Newman JC, Verdin E. Ketone bodies as signaling metabolites. Trends Endocrinol Metab. 2014;25(1):42-52.

19. Huang D, Li T, Wang L, Zhang L, Yan R, Li K, Xing S, Wu G, Hu L, Jia W et al. Hepatocellular carcinoma redirects to ketolysis for progression under nutrition deprivation stress. Cell Res. 2016;26(10):1112-30.

20. Vriens K, Christen S, Parik S, Broekaert D, Yoshinaga K, Talebi A Dehairs J, Escalona-Noguero C, Schmieder R, Cornfield T, et al. Evidence for an alternative fatty acid desaturation pathway increasing cancer plasticity. Nature. 2019;566(7744):403-6.

21. Keshet R, Szlosarek P, Carracedo A, Erez A. Rewiring urea cycle metabolism in cancer to support anabolism. Nat Rev Cancer. 2018:18(10):634-45.

22. Li L, Mao Y, Zhao L, Li L, Wu J, Zhao M, Du W, Yu L, Jiang P. p53 regulation of ammonia metabolism through urea cycle controls polyamine biosynthesis. Nature. 2019;567(7747):253-6.

23. Spinelli JB, Yoon H, Ringel AE, Jeanfavre S, Clish CB, Haigis MC. Metabolic recycling of ammonia via glutamate dehydrogenase supports breast cancer biomass. Science. 2017;358(6365):941-6.

24. Kim J, Hu Z, Cai L, Li K, Choi E, Faubert B, Bezwada D, RodriguezCanales J, Villalobos P, Lin YF, et al. CPS1 maintains pyrimidine pools and DNA synthesis in KRAS/LKB1-mutant lung cancer cells. Nature. 2017;546(7656):168-72.

25. Lee JS, Adler L, Karathia H, Carmel N, Rabinovich S, Auslander N, Keshet R, Stettner N, Silberman A, Agemy L, et al. Urea cycle dysregulation generates clinically relevant genomic and biochemical signatures. Cell. 2018;174(6):1559-1570.e1522.

26. Bi J, Wu S, Zhang W, Mischel PS. Targeting cancer's metabolic codependencies: a landscape shaped by genotype and tissue context. Biochim Biophys Acta Rev Cancer. 2018;1870(1):76-87.

27. Kim J, DeBerardinis RJ. Mechanisms and implications of metabolic heterogeneity in cancer. Cell Metab. 2019;30(3):434-46.

28. Goncalves MD, Hopkins BD, Cantley LC. Phosphatidylinositol 3-kinase, growth disorders, and cancer. N Engl J Med. 2018;379(21):2052-62.

29. Pupo E, Avanzato D, Middonti E, Bussolino F, Lanzetti L. KRAS-driven metabolic rewiring reveals novel actionable targets in cancer. Front Oncol. 2019;9:848.

30. Commisso C, Davidson SM, Soydaner-Azeloglu RG, Parker SJ, Kamphorst JJ, Hackett S, Grabocka E, Nofal M, Drebin JA, Thompson CB, et al. Macropinocytosis of protein is an amino acid supply route in Ras-transformed cells. Nature. 2013;497(7451):633-7. 
31. Stine ZE, Walton ZE, Altman BJ, Hsieh AL, Dang CV. MYC, metabolism, and cancer. Cancer Discov. 2015;5(10):1024-39.

32. Kruiswijk F, Labuschagne CF, Vousden KH. p53 in survival, death and metabolic health: a lifeguard with a licence to kill. Nat Rev Mol Cell Biol. 2015;16(7):393-405

33. Dang L, White DW, Gross $S$, Bennett BD, Bittinger MA, Driggers EM, Fantin VR, Jang HG, Jin S, Keenan MC, et al. Cancer-associated IDH1 mutations produce 2-hydroxyglutarate. Nature. 2009;462(7274):739-44.

34. Ward PS, Patel J, Wise DR, Abdel-Wahab O, Bennett BD, Coller HA, Cross JR, Fantin VR, Hedvat CV, Perl AE, et al. The common feature of leukemia-associated IDH1 and IDH2 mutations is a neomorphic enzyme activity converting alpha-ketoglutarate to 2-hydroxyglutarate. Cancer Cell. 2010;17(3):225-34.

35. Xiao M, Yang H, Xu W, Ma S, Lin H, Zhu H, Liu L, Liu Y, Yang C, Xu Y, et al. Inhibition of alpha-KG-dependent histone and DNA demethylases by fumarate and succinate that are accumulated in mutations of $\mathrm{FH}$ and SDH tumor suppressors. Genes Dev. 2012;26(12):1326-38.

36. Hu J, Locasale JW, Bielas JH, O'Sullivan J, Sheahan K, Cantley LC, Vander Heiden MG, Vitkup D. Heterogeneity of tumor-induced gene expression changes in the human metabolic network. Nat Biotechnol. 2013;31(6):522-9.

37. Gaude E, Frezza C. Tissue-specific and convergent metabolic transformation of cancer correlates with metastatic potential and patient survival. Nat Commun. 2016;7:13041.

38. Yuneva MO, Fan TW, Allen TD, Higashi RM, Ferraris DV, Tsukamoto T, Mates JM, Alonso FJ, Wang C, Seo Y, et al. The metabolic profile of tumors depends on both the responsible genetic lesion and tissue type. Cell Metab. 2012;15(2):157-70.

39. Mayers JR, Torrence ME, Danai LV, Papagiannakopoulos T, Davidson SM, Bauer MR, Lau AN, Ji BW, Dixit PD, Hosios AM, et al. Tissue of origin dictates branched-chain amino acid metabolism in mutant Kras-driven cancers. Science. 2016;353(6304):1161-5.

40. Davidson SM, Papagiannakopoulos T, Olenchock BA, Heyman JE, Keibler MA, Luengo A, Bauer MR, Jha AK, O'Brien JP, Pierce KA, et al. Environment impacts the metabolic dependencies of ras-driven non-small cell lung cancer. Cell Metab. 2016;23(3):517-28.

41. Cantor JR, Abu-Remaileh M, Kanarek N, Freinkman E, Gao X, Louissaint A Jr, Lewis CA, Sabatini DM. Physiologic medium rewires cellular metabolism and reveals uric acid as an endogenous inhibitor of UMP synthase. Cell. 2017;169(2):258-272.e217.

42. Hensley CT, Faubert B, Yuan Q, Lev-Cohain N, Jin E, Kim J, Jiang L, Ko B, Skelton R, Loudat L, et al. Metabolic Heterogeneity in Human Lung Tumors. Cell. 2016;164(4):681-94.

43. Mashimo T, Pichumani K, Vemireddy V, Hatanpaa KJ, Singh DK, Sirasanagandla S, Nannepaga S, Piccirillo SG, Kovacs Z, Foong C, et al. Acetate is a bioenergetic substrate for human glioblastoma and brain metastases. Cell. 2014;159(7):1603-14.

44. Spencer JA, Ferraro F, Roussakis E, Klein A, Wu J, Runnels JM, Zaher W, Mortensen $L$, Alt C, Turcotte R, et al. Direct measurement of local oxygen concentration in the bone marrow of live animals. Nature. 2014:508(7495):269-73.

45. Zhang W, Bado I, Wang H, Lo HC, Zhang XH. Bone metastasis: find your niche and fit in. Trends Cancer. 2019:5(2):95-110.

46. Fornetti J, Welm AL, Stewart SA. Understanding the Bone In Cancer Metastasis. J Bone Miner Res. 2018;33(12):2099-113.

47. He F, Chiou AE, Loh HC, Lynch M, Seo BR, Song YH, Lee MJ, Hoerth R, Bortel EL, Willie BM, et al. Multiscale characterization of the mineral phase at skeletal sites of breast cancer metastasis. Proc Natl Acad Sci U S A. 2017;114(40):10542-7.

48. O'Grady S, Morgan MP. Microcalcifications in breast cancer: from pathophysiology to diagnosis and prognosis. Biochim Biophys Acta Rev Cancer. 2018;1869(2):310-20.

49. Cooke MM, McCarthy GM, Sallis JD, Morgan MP. Phosphocitrate inhibits calcium hydroxyapatite induced mitogenesis and upregulation of matrix metalloproteinase-1, interleukin-1 beta and cyclooxygenase-2 mRNA in human breast cancer cell lines. Breast Cancer Res Treat. 2003;79(2):253-63.

50. Liao J, Schneider A, Datta NS, McCauley LK. Extracellular calcium as a candidate mediator of prostate cancer skeletal metastasis. Cancer Res. 2006;66(18):9065-73.
51. Saidak Z, Boudot C, Abdoune R, Petit L, Brazier M, Mentaverri R, Kamel $S$. Extracellular calcium promotes the migration of breast cancer cells through the activation of the calcium sensing receptor. Exp Cell Res. 2009;315(12):2072-80.

52. Joeckel E, Haber T, Prawitt D, Junker K, Hampel C, Thuroff JW, Roos FC, Brenner W. High calcium concentration in bones promotes bone metastasis in renal cell carcinomas expressing calcium-sensing receptor. Mol Cancer. 2014;13:42.

53. Nakazawa MS, Keith B, Simon MC. Oxygen availability and metabolic adaptations. Nat Rev Cancer. 2016;16(10):663-73.

54. Hiraga T, Kizaka-Kondoh S, Hirota K, Hiraoka M, Yoneda T. Hypoxia and hypoxia-inducible factor-1 expression enhance osteolytic bone metastases of breast cancer. Cancer Res. 2007;67(9):4157-63.

55. Cox TR, Rumney RMH, Schoof EM, Perryman L, Hoye AM, Agrawal A, Bird D, Latif NA, Forrest $\mathrm{H}$, Evans HR, et al. The hypoxic cancer secretome induces pre-metastatic bone lesions through lysyl oxidase. Nature. 2015;522(7554):106-10.

56. Yoneda T, Hiasa M, Nagata Y, Okui T, White F. Contribution of acidic extracellular microenvironment of cancer-colonized bone to bone pain. Biochim Biophys Acta. 2015:1848:2677-84.

57. Ogawa T, Ishida-Kitagawa N, Tanaka A, Matsumoto T, Hirouchi T, Akimaru M, Tanihara M, Yogo K, Takeya T. A novel role of L-serine (L-Ser) for the expression of nuclear factor of activated T cells (NFAT)2 in receptor activator of nuclear factor kappa B ligand (RANKL)-induced osteoclastogenesis in vitro. J Bone Miner Metab. 2006;24(5):373-9.

58. Pollari S, Kakonen SM, Edgren H, Wolf M, Kohonen P, Sara H, Guise T, Nees M, Kallioniemi O. Enhanced serine production by bone metastatic breast cancer cells stimulates osteoclastogenesis. Breast Cancer Res Treat. 2011;125(2):421-30.

59. Lemma S, Di Pompo G, Porporato PE, Sboarina M, Russell S, Gillies RJ, Baldini N, Sonveaux P. Avnet S. MDA-MB-231 breast cancer cells fuel osteoclast metabolism and activity: a new rationale for the pathogenesis of osteolytic bone metastases. Biochim Biophys Acta Mol Basis Dis. 2017;1863(12):3254-64

60. Wang H, Tian L, Liu J, Goldstein A, Bado I, Zhang W, Arenkiel BR, Li Z, Yang M, Du S, et al. The osteogenic niche is a calcium reservoir of bone micrometastases and confers unexpected therapeutic vulnerability. Cancer Cell. 2018:34(5):823-839.e827.

61. Gazi E, Gardner P, Lockyer NP, Hart CA, Brown MD, Clarke NW. Direct evidence of lipid translocation between adipocytes and prostate cancer cells with imaging FTIR microspectroscopy. J Lipid Res. 2007:48(8):1846-56.

62. Brown MD, Hart C, Gazi E, Gardner P, Lockyer N, Clarke N. Influence of omega-6 PUFA arachidonic acid and bone marrow adipocytes on metastatic spread from prostate cancer. Br J Cancer. 2010;102(2):403-13.

63. Herroon MK, Rajagurubandara E, Hardaway AL, Powell K, Turchick A, Feldmann D, Podgorski I. Bone marrow adipocytes promote tumor growth in bone via FABP4-dependent mechanisms. Oncotarget. 2013:4(11):2108-23.

64. Diedrich JD, Rajagurubandara E, Herroon MK, Mahapatra G, Huttemann M, Podgorski I. Bone marrow adipocytes promote the Warburg phenotype in metastatic prostate tumors via HIF-1alpha activation. Oncotarget. 2016;7(40):64854-77.

65. Dai J, Escara-Wilke J, Keller JM, Jung Y, Taichman RS, Pienta KJ, Keller ET. Primary prostate cancer educates bone stroma through exosomal pyruvate kinase M2 to promote bone metastasis. J Exp Med. 2019;216(12):2883-99.

66. Augustin HG, Koh GY. Organotypic vasculature: From descriptive heterogeneity to functional pathophysiology. Science. 2017. https://doi. org/10.1126/science.aal2379.

67. Brodt P. Role of the microenvironment in liver metastasis: from pre- to prometastatic niches. Clin Cancer Res. 2016:22(24):5971-82.

68. Rossetto A, De Re V, Steffan A, Ravaioli M, Miolo G, Leone P, Racanelli V, Uzzau A, Baccarani U, Cescon M. Carcinogenesis and metastasis in liver. Cancers (Basel). 2019;11(11):1731.

69. Jang C, Hui S, Lu W, Cowan AJ, Morscher RJ, Lee G, Liu W, Tesz GJ, Birnbaum MJ, Rabinowitz JD. The small intestine converts dietary fructose into glucose and organic acids. Cell Metab. 2018;27(2):351-361.e353.

70. Bu P, Chen KY, Xiang K, Johnson C, Crown SB, Rakhilin N, Ai Y, Wang L, Xi R, Astapova I, et al. Aldolase B-mediated fructose metabolism drives 
metabolic reprogramming of colon cancer liver metastasis. Cell Metab. 2018;27(6):1249-1262.e1244.

71. Teng S, Li YE, Yang M, Qi R, Huang Y, Wang Q, Zhang Y, Chen S, Li S, Lin $\mathrm{K}$, et al. Tissue-specific transcription reprogramming promotes liver metastasis of colorectal cancer. Cell Res. 2020;30(1):34-49.

72. Loo JM, Scherl A, Nguyen A, Man FY, Weinberg E, Zeng Z, Saltz L, Paty PB, Tavazoie SF. Extracellular metabolic energetics can promote cancer progression. Cell. 2015;160(3):393-406.

73. Dupuy F, Tabaries S, Andrzejewski S, Dong Z, Blagih J, Annis MG, Omeroglu A, Gao D, Leung S, Amir E, et al. PDK1-dependent metabolic reprogramming dictates metastatic potential in breast cancer. Cell Metab. 2015;22(4):577-89.

74. Fabian A, Stegner S, Miarka L, Zimmermann J, Lenk L, Rahn S, Buttlar J, Viol F, Knaack H, Esser D, et al. Metastasis of pancreatic cancer: An uninflamed liver micromilieu controls cell growth and cancer stem cell properties by oxidative phosphorylation in pancreatic ductal epithelial cells. Cancer Lett. 2019;453:95-106.

75. Altorki NK, Markowitz GJ, Gao D, Port JL, Saxena A, Stiles B, McGraw T, Mittal $V$. The lung microenvironment: an important regulator of tumour growth and metastasis. Nat Rev Cancer. 2019;19(1):9-31.

76. Alvarado A, Arce I. Metabolic functions of the lung, disorders and associated pathologies. J Clin Med Res. 2016;8(10):689-700.

77. Davis RT, Blake K, Ma D, Gabra MBI, Hernandez GA, Phung AT, Yang $Y$, Maurer D, Lefebvre A, Alshetaiwi $H$, et al. Transcriptional diversity and bioenergetic shift in human breast cancer metastasis revealed by single-cell RNA sequencing. Nat Cell Biol. 2020;22(3):310-20.

78. Bost F, Kaminski L. The metabolic modulator PGC-1alpha in cancer. Am J Cancer Res. 2019;9(2):198-211.

79. LeBleu VS, O'Connell JT, Gonzalez Herrera KN, Wikman H, Pantel K, Haigis MC, de Carvalho FM, Damascena A, Domingos Chinen LT, Rocha RM, et al. PGC-1alpha mediates mitochondrial biogenesis and oxidative phosphorylation in cancer cells to promote metastasis. Nat Cell Biol. 2014. https://doi.org/10.1038/ncb3039.

80. Andrzejewski S, Klimcakova E, Johnson RM, Tabaries S, Annis MG, McGuirk S, Northey JJ, Chenard V, Sriram U, Papadopoli DJ, et al. PGC1alpha promotes breast cancer metastasis and confers bioenergetic flexibility against metabolic drugs. Cell Metab. 2017;26(5):778-787.e775.

81. Halliwell B. Cell culture, oxidative stress, and antioxidants: avoiding pitfalls. Biomed J. 2014;37(3):99-105.

82. Stresing V, Baltziskueta E, Rubio N, Blanco J, Arriba MC, Valls J, Janier M, Clezardin P, Sanz-Pamplona R, Nieva C, et al. Peroxiredoxin 2 specifically regulates the oxidative and metabolic stress response of human metastatic breast cancer cells in lungs. Oncogene. 2013;32(6):724-35.

83. Basnet $\mathrm{H}$, Tian L, Ganesh K, Huang YH, Macalinao DG, Brogi E, Finley LW, Massague J. Flura-seq identifies organ-specific metabolic adaptations during early metastatic colonization. Elife. 2019. https://doi.org/10. 7554/eLife.43627.

84. Schafer ZT, Grassian AR, Song L, Jiang Z, Gerhart-Hines Z, Irie HY, Gao S, Puigserver P, Brugge JS. Antioxidant and oncogene rescue of metabolic defects caused by loss of matrix attachment. Nature. 2009:461(7260):109-13.

85. Piskounova E, Agathocleous M, Murphy MM, Hu Z, Huddlestun SE, Zhao Z, Leitch AM, Johnson TM, DeBerardinis RJ, Morrison SJ. Oxidative stress inhibits distant metastasis by human melanoma cells. Nature. 2015:527(7577):186-91.

86. Shinde A, Wilmanski T, Chen H, Teegarden D, Wendt MK. Pyruvate carboxylase supports the pulmonary tropism of metastatic breast cancer Breast Cancer Res. 2018;20(1):76.

87. Christen S, Lorendeau D, Schmieder R, Broekaert D, Metzger K, Veys K, Elia I, Buescher JM, Orth MF, Davidson SM, et al. Breast cancer-derived lung metastases show increased pyruvate carboxylase-dependent anaplerosis. Cell Rep. 2016;17(3):837-48.

88. Sellers K, Fox MP, Bousamra M 2nd, Slone SP, Higashi RM, Miller DM, Wang Y, Yan J, Yuneva MO, Deshpande R, et al. Pyruvate carboxylase is critical for non-small-cell lung cancer proliferation. J Clin Invest. 2015;125(2):687-98.

89. Elia I, Rossi M, Stegen S, Broekaert D, Doglioni G, van Gorsel M, Boon R, Escalona-Noguero C, Torrekens S, Verfaillie C, et al. Breast cancer cells rely on environmental pyruvate to shape the metastatic niche. Nature. 2019;568(7750):117-21.
90. van Weverwijk A, Koundouros N, Iravani M, Ashenden M, Gao Q, Poulogiannis $\mathrm{G}$, Jungwirth $\mathrm{U}$, Isacke $\mathrm{CM}$. Metabolic adaptability in metastatic breast cancer by AKR1B10-dependent balancing of glycolysis and fatty acid oxidation. Nat Commun. 2019;10(1):2698.

91. Elia I, Broekaert D, Christen S, Boon R, Radaelli E, Orth MF, Verfaillie C, Grunewald TGP, Fendt SM. Proline metabolism supports metastasis formation and could be inhibited to selectively target metastasizing cancer cells. Nat Commun. 2017:8:15267.

92. Knott SRV, Wagenblast E, Khan S, Kim SY, Soto M, Wagner M, Turgeon MO, Fish L, Erard N, Gable AL, et al. Asparagine bioavailability governs metastasis in a model of breast cancer. Nature. 2018;554(7692):378-81.

93. Minn AJ, Gupta GP, Siegel PM, Bos PD, Shu W, Giri DD, Viale A, Olshen $A B$, Gerald WL, Massague J. Genes that mediate breast cancer metastasis to lung. Nature. 2005;436(7050):518-24.

94. Achrol AS, Rennert RC, Anders C, Soffietti R, Ahluwalia MS, Nayak L, Peters S, Arvold ND, Harsh GR, Steeg PS, et al. Brain metastases. Nat Rev Dis Primers. 2019;5(1):5.

95. Boire A, Brastianos PK, Garzia L, Valiente M. Brain metastasis. Nat Rev Cancer. 2020;20(1):4-11.

96. Chen El, Hewel J, Krueger JS, Tiraby C, Weber MR, Kralli A, Becker K, Yates JR 3rd, Felding-Habermann B. Adaptation of energy metabolism in breast cancer brain metastases. Cancer Res. 2007;67(4):1472-86.

97. Fischer GM, Jalali A, Kircher DA, Lee WC, McQuade JL, Haydu LE, Joon AY, Reuben A, de Macedo MP, Carapeto FCL, et al. Molecular profiling reveals unique immune and metabolic features of melanoma brain metastases. Cancer Discov. 2019;9(5):628-45.

98. Maher EA, Marin-Valencia I, Bachoo RM, Mashimo T, Raisanen J, Hatanpaa KJ, Jindal A, Jeffrey FM, Choi C, Madden C, et al. Metabolism of [U-13 C]glucose in human brain tumors in vivo. NMR Biomed. 2012;25(11):1234-44.

99. Cordero A, Kanojia D, Miska J, Panek WK, Xiao A, Han Y, Bonamici N, Zhou W, Xiao T, Wu M, et al. FABP7 is a key metabolic regulator in HER2 + breast cancer brain metastasis. Oncogene. 2019;38(37):6445-60

100. Chen J, Lee HJ, Wu X, Huo L, Kim SJ, Xu L, Wang Y, He J, Bollu LR, Gao G, et al. Gain of glucose-independent growth upon metastasis of breast cancer cells to the brain. Cancer Res. 2015;75(3):554-65.

101. Neman J, Termini J, Wilczynski S, Vaidehi N, Choy C, Kowolik CM, Li H, Hambrecht AC, Roberts E, Jandial R. Human breast cancer metastases to the brain display GABAergic properties in the neural niche. Proc Natl Acad Sci U S A. 2014;111(3):984-9.

102. Danbolt NC. Glutamate uptake. Prog Neurobiol. 2001;65(1):1-105.

103. Zeng Q, Michael IP, Zhang P, Saghafinia S, Knott G, Jiao W, McCabe BD, Galvan JA, Robinson HPC, Zlobec I, et al. Synaptic proximity enables NMDAR signalling to promote brain metastasis. Nature. 2019;573(7775):526-31.

104. Lin Q, Balasubramanian K, Fan D, Kim SJ, Guo L, Wang H, Bar-Eli M, Aldape KD, Fidler IJ. Reactive astrocytes protect melanoma cells from chemotherapy by sequestering intracellular calcium through gap junction communication channels. Neoplasia. 2010;12(9):748-54.

105. Chen Q, Boire A, Jin X, Valiente M, Er EE, Lopez-Soto A, Jacob L, Patwa R, Shah $\mathrm{H}$, Xu K, et al. Carcinoma-astrocyte gap junctions promote brain metastasis by cGAMP transfer. Nature. 2016;533(7604):493-8.

106. Bos PD, Zhang XH, Nadal C, Shu W, Gomis RR, Nguyen DX, Minn AJ, van de Vijver MJ, Gerald WL, Foekens JA, et al. Genes that mediate breast cancer metastasis to the brain. Nature. 2009:459(7249):1005-9.

107. Allen JE, Patel AS, Prabhu WV, Dicker DT, Sheehan JM, Glantz MJ, EI-Deiry WS. COX-2 drives metastatic breast cells from brain lesions into the cerebrospinal fluid and systemic circulation. Cancer Res. 2014;74(9):2385-90.

108. Chkourko Gusky H, Diedrich J, MacDougald OA, Podgorski I. Omentum and bone marrow: how adipocyte-rich organs create tumour microenvironments conducive for metastatic progression. Obes Rev. 2016;17(11):1015-29.

109. Nieman KM, Kenny HA, Penicka CV, Ladanyi A, Buell-Gutbrod R, Zillhardt MR, Romero IL, Carey MS, Mills GB, Hotamisligil GS, et al. Adipocytes promote ovarian cancer metastasis and provide energy for rapid tumor growth. Nat Med. 2011;17(11):1498-503.

110. Ladanyi A, Mukherjee A, Kenny HA, Johnson A, Mitra AK, Sundaresan S, Nieman KM, Pascual G, Benitah SA, Montag A, et al. Adipocyte-induced CD36 expression drives ovarian cancer progression and metastasis. Oncogene. 2018;37(17):2285-301. 
111. John B, Naczki C, Patel C, Ghoneum A, Qasem S, Salih Z, Said N. Regulation of the bi-directional cross-talk between ovarian cancer cells and adipocytes by SPARC. Oncogene. 2019;38(22):4366-83.

112. Miranda F, Mannion D, Liu S, Zheng Y, Mangala LS, Redondo C, HerreroGonzalez S, Xu R, Taylor C, Chedom DF, et al. Salt-inducible kinase 2 couples ovarian cancer cell metabolism with survival at the adipocyterich metastatic niche. Cancer Cell. 2016;30(2):273-89.

113. Salimian Rizi B, Caneba C, Nowicka A, Nabiyar AW, Liu X, Chen K, Klopp A, Nagrath D. Nitric oxide mediates metabolic coupling of omentumderived adipose stroma to ovarian and endometrial cancer cells. Cancer Res. 2015;75(2):456-71.

114. Curtis M, Kenny HA, Ashcroft B, Mukherjee A, Johnson A, Zhang Y, Helou Y, Batlle R, Liu X, Gutierrez N, et al. Fibroblasts mobilize tumor cell glycogen to promote proliferation and metastasis. Cell Metab. 2019;29(1):141-155.e149.

115. Pereira ER, Kedrin D, Seano G, Gautier O, Meijer EFJ, Jones D, Chin SM, Kitahara S, Bouta EM, Chang J, et al. Lymph node metastases can invade local blood vessels, exit the node, and colonize distant organs in mice. Science. 2018;359(6382):1403-7.

116. Brown M, Assen FP, Leithner A, Abe J, Schachner H, Asfour G, BagoHorvath Z, Stein JV, Uhrin P, Sixt M, et al. Lymph node blood vessels provide exit routes for metastatic tumor cell dissemination in mice. Science. 2018;359(6382):1408-11.

117. Naxerova K, Reiter JG, Brachtel E, Lennerz JK, van de Wetering M, Rowan A, Cai T, Clevers H, Swanton C, Nowak MA, et al. Origins of lymphatic and distant metastases in human colorectal cancer. Science. 2017:357(6346):55-60
118. Lee CK, Jeong SH, Jang C, Bae H, Kim YH, Park I, Kim SK, Koh GY. Tumor metastasis to lymph nodes requires YAP-dependent metabolic adaptation. Science. 2019;363(6427):644-9.

119. Shang C, Wang W, Liao Y, Chen Y, Liu T, Du Q, Huang J, Liang Y, Liu J, Zhao Y, et al. LNMICC promotes nodal metastasis of cervical cancer by reprogramming fatty acid metabolism. Cancer Res. 2018;78(4):877-90.

120. Hung PF, Hong TM, Chang CC, Hung CL, Hsu YL, Chang YL, Wu CT, Chang GC, Chan NL, Yu SL, et al. Hypoxia-induced Slug SUMOylation enhances lung cancer metastasis. J Exp Clin Cancer Res. 2019:38(1):5.

121. Zhang Z, LiTE, Chen M, Xu D, Zhu Y, Hu BY, Lin ZF, Pan JJ, Wang X, Wu C, et al. MFN1-dependent alteration of mitochondrial dynamics drives hepatocellular carcinoma metastasis by glucose metabolic reprogramming. Br J Cancer. 2020;122(2):209-20.

122. Elia I, Doglioni G, Fendt SM. Metabolic hallmarks of metastasis formation. Trends Cell Biol. 2018;28(8):673-84.

123. Chao M, Wu H, Jin K, Li B, Wu J, Zhang G, Yang G, Hu X. A nonrandomized cohort and a randomized study of local control of large hepatocarcinoma by targeting intratumoral lactic acidosis. Elife. 2016. https://doi.org/10.7554/eLife.15691.

\section{Publisher's Note}

Springer Nature remains neutral with regard to jurisdictional claims in published maps and institutional affiliations.
Ready to submit your research? Choose BMC and benefit from:

- fast, convenient online submission

- thorough peer review by experienced researchers in your field

- rapid publication on acceptance

- support for research data, including large and complex data types

- gold Open Access which fosters wider collaboration and increased citations

- maximum visibility for your research: over $100 \mathrm{M}$ website views per year

At BMC, research is always in progress.

Learn more biomedcentral.com/submissions 